\title{
UUTEST PEREKONNANIMEDEST EESTI-INGERIS JA NENDE PANEKUST 1922. AASTAL
}

\author{
ENN ERNITS
}

Annotatsioon. Artikkel põhineb osaliselt Emakeele Seltsi kõnekoosolekul 12. mail 2015 Tallinnas peetud ettekandel „Eesti-Ingeri isikunimedest läbi aegade“. Kirjutises antakse kõigepealt lühiülevaade Eesti-Ingeri ehk Narva valla rahvuslikust koosseisust 1920. aastate alguses. Sealsetel luteriusulistel eestlastel ja soomlastel olid sobilikud perekonnanimed enamasti olemas. Neid tahtsid muuta vaid vähesed soomlased ja üksikud eestlased. Õigeusklikel isuritel ja vadjalastel olid vene perekonnanimed, mille asemele tuli võtta läänemeresoomepärased. Kirjutises eristatakse tähendusrühmade järgi 1) eestipäraseid, 2) soome- ja isuripäraseid ning 3) muid uusi perekonnanimesid. Keskendutakse nende algupärale, tähendustele ja võimalikele lätetele, samuti seostele endiste venepäraste perekonnanimedega.

Võtmesõnad: Eesti-Ingeri, läänemeresoome keeled, onomastika, antroponüümid, perekonnanimed

\section{Sissejuhatus}

Tartu rahulepingu põhjal liideti Eesti Vabariigiga Narva jõe paremal kaldal asuvad maad ehk osa Narvatagusest (vn Занаровье), mis seni oli kuulunud Peterburi kubermangu. 1920. aastal moodustati Narva taga kolm valda: Naroova (pärastpoole Narva), Kose (1939-1945 Piiri) ja Skarjatina (ka Karjati, 1939-1945 Raja). Narva vald oli killuke ajaloolisest Ingerimaast, mistõttu seda nimetati ka Eesti-Ingeriks. Aastatel 1945-1946 viidi nimetatud ala uuesti Venemaa koosseisu.

1922. aastal asendati Eesti-Ingeris venepärased ja ebameeldivana tunduvad perekonnanimed uutega. Sellest andsid lühikesi ülevaateid nimede eestistamist koordineerinud ministeeriumitöötaja Samuel Sommer (1922b, 1923a, 1923b) ja põhiliselt nimekomisjonide tehnilise abijõuna 
tegutsenud filoloog Villem Ernits (2013/1922, 2013/1925). Viimane loetles muu hulgas Narva valla külades valitud endisi ja uusi perekonnanimesid, tõsi küll, neid lähemalt analüüsimata. Kümmekonna aasta taha jääb Peterburi arstist keeleuurija ja koduloolase Aleksei Krjukovi (2007: $138,139)$ põgus ülevaade Narvataguse isurite eestistatud ja soomestatud perekonnanimedest. Peamiselt varasematele kirjutistele toetudes on kirjeldanud perekonnanimede panemist Narva taga ning võrrelnud seda Setumaal toimunuga üliõpilane Kati Nurka oma bakalaureusetöös (2010). Muide, Eesti-Ingerist on tal vaid 22 nimenäidet. Huvipakkuvat teavet nimepanekuga seondunud meeleolude kohta on jaganud Väiküla isuri päritolu kodu-uurija Boriss Jemeljanov (Jõgi). Ta avaldas arhiivimaterjalide põhjal tabelid Väiküla rahva endiste ja 1922. aastal pandud perekonnanimede kohta (Emel'anov 2011: 136-139, 350-354). Just need loendid innustasid siinkirjutajat asjaomast teemat käsile võtma.

Kirjutises käsitletakse kõiki Eesti-Ingeris 1922. aastal võetud perekonnanimesid arhiivis säilitatavate nimepanekuprotokollide põhjal (EAA 5433.1.5). Vaatluse alt jääb välja Narva jõe taha jääv Jaanilinn, mis kuulus Narva linna koosseisu. Põhitähelepanu pööratakse uute perekonnanimede päritolule ja semantikale, samuti seostele endiste perekonnanimedega.

\section{Eesti-Ingeri asustusest}

Ajaloolase Tiit Rosenbergi (2013: 129) järgi elas 1922. aasta rahvaloenduse andmeil Eesti-Ingeris 2799 inimest: 1765 venelast (63\% elanikkonnast), 684 isurit ja ingerisoomlast (24\%) ning 350 eestlast (13\%). Paraku on andmed Narva valla külade 1920. aasta etnilise struktuuri kohta eksitavad, sest tabel hõlmab ka külasid, mis Eesti-Ingeri koosseisu ei kuulunud, nagu Haavikko (vn Кейкино), Kotko (Орль), Mannakka (Манновка) ja Tiensuu (Извоз); teisalt aga puuduvad Hannike, Kallivere, Vanaküla jt läänemeresoome külad (vrd Rosenberg 2013: 131 ja Üldrahvalugemise 1924: 23).

Nimepaneku seisukohast pakub erilist huvi külades elanud õigeusklike isurite arv, sest neil olid Eesti Vabariigi toonase nimepoliitika seisukohast ebasoovitavad vene perekonnanimed, mis tuli asendada läänemeresoomepärastega. Ent isurite arvu teadasaamine on üsna komplitseeritud. Selle üks põhjusi on erinevad lähtekohad. Tulemused olenevad lähtealusest: kas peetakse silmas geneetilist päritolu või keelt ja kultuuri; kas toetutakse enesemääratlusele või ametniku/uurija hinnangule. 1922. aasta rahvaloenduse 
andmed valdade kohta põhinevad inimeste küsitlusel nende tavakeele kohta (rahvaloenduse küsimus Mis keelt harilikult eraelus kõneleb?), mistõttu selliseid rahvaloendusi peetakse poliitilisteks ja identiteeti konstrueerivateks, seega tänapäeva mõistes metoodiliselt ebasoovitatavateks (Koreinik, Tender 2014: 80, 83). Peale selle pole 1922. aasta rahvaloendusel eristatud isureid ja ingerisoomlasi ega üldse neid esile toodudki, vaid paigutatud muude rahvuste rubriiki (vt Üldrahvalugemise 1924: tabel 5).

Teistsugused andmed pärinevad Villem Ernitsalt, kelle järgi elas Narva vallas 1027 isurit (sh Väikülas 17 isuristunud poolakat), 545 soomlast, 47 eestlast, 2 vadjalast, 1 karjalane ja 216 venelast. Viimaste hulgas eristati üht venestunud leedulast ja kolme täisvenestunud soome perekonda, 16 vene naist isuri perekondades ja 17 isuri naist vene perekondades (V. Ernits 2013/1925: 254). Mõne küla venelaste kohta saab teavet ka 1922. aastal pandud perekonnanimede järgi. Nii registreeriti Karstalas 25 vene, kaks eesti ja kaks soome perekonnanime, Dolgaja Niivas 17 vene ja üks eesti perekonnanimi ning Uuskülas üks vene ja kaks eesti perekonnanime. Nimepanekuprotokollide järgi olid Eesti-Ingeris puhtvene külad Komarovka, Popovka, Zahhonje ja Zaretšje. Kaheksa küla (Uue-Arssi, Lommi, Smolka ehk Tõrvala jt) kohta pole protokollides mingit teavet (vrd Üldrahvalugemise 1924: 23). Selle põhjal võiks oletada, et neis külades ei elanud vene perekonnanimega isikuid.

Villem Ernits esitab andmeid ka Narva valla külade rahvusliku koosseisu kohta (vt tabel 1; vadjalaste arvu pole märgitud; V. Ernits 2013/1925). Külad on järjestatud kahanevalt isurite arvu järgi. Need andmed põhinevad kõrvalseisja hinnangutel rahvuste kohta ajaloolis-geneetilisest seisukohast lähtudes. Kindlasti ei saa Ernitsa esitatud numbreid võtta absoluutse tõe pähe. Näiteks Samuel Sommer (1922b), kes kirjeldas oma artiklis vaid paari Eesti-Ingeri küla, loendas Hannikas 81 inimest, neist 53 isurit ja 28 ingerisoomlast.

Narva valla isurid (eriti noorem põlv) olid toona keele ja kultuuri poolest tugevasti venestunud ning suhtusid noore Eesti Vabariigi tegemistesse kas umbusklikult või lausa vaenulikult. Veendunult peeti endid venelasteks. Täiskasvanud suhtlesid omavahel meelsamini vene keeles, kuigi valdasid isuri keelt, lapsi kõnetati ainult vene keeles. Venestamisele aitasid jõuliselt kaasa kohalikud kooliõpetajad ja papid. Käis agar võitlus vene õppekeele kasutamise eest kohalikes koolides (vt lähemalt E. Ernits 2009: $44 \mathrm{jj})$. 


\section{Perekonnanimed 1922. aastani}

Luteriusulistel eestlastel ja soomlastel olid üldiselt eesti- või soomepärased perekonnanimed. Vaid mõni eesti nimi võis aja jooksul olla muutunud venepäraseks. Seevastu õigeusklikel vadjalastel ja isuritel olid vene perekonnanimed, mis vaid vähestel juhtudel seostusid läänemeresoome keelte sõnadega. Venemaa dokumentides käibis sajandeid nimesüsteem, mille järgi isikuid märgiti eesnime ning isanime või hüüdnimega, nt Ivan Mikitin ja Griška Lisitsa 'rebane'. Kohustuslikke perekonnanimesid hakati XVI sajandil nõudma kõigepealt vürstidelt ja bojaaridelt, seejärel madalamatelt aadlikelt ja suurkaupmeestelt. Talupoegadel ilmusid esimesed perekonnanimed XVI-XVIII sajandil (nt Ivan Sussanin), kuid kinnistusid lõplikult alles pärisorjuse kaotamise järel 1861. aastal. Ometi polnud Venemaa 1896. aasta rahvaloenduse järgi perekonnanimesid veel üle poolel elanikkonnast (Istorija; Russkie familii). Perekonnanimed said talumehed sõjaväeteenistusse kutsumisel. Need moodustati sagedasti vanaisa eesnime järgi (Emel'anov 2011: 134, 349) ja ei kandunud üle lastele. Ent Narva vallas leidus ka teistsuguseid perekonnanimesid.

Tabel 1. Läänemeresoomlaste arv Narva valla külades ${ }^{1}$

\begin{tabular}{|l|c|c|c|}
\hline Küla (eesti ja vene nimi) & Isurid & $\begin{array}{r}\text { Ingeri- } \\
\text { soomlased }\end{array}$ & Eestlased \\
\hline Väiküla (Венкуль, Венекюля, Наровское) & 483 & - & 4 \\
\hline Vanaküla (Илькино) & 173 & 44 & 1 \\
\hline Saarküla (Саркюля) & 142 & - & 14 \\
\hline Kallivere (Фитинка) & 105 & 233 & 2 \\
\hline Hannika (Ханике) & 43 & 88 & - \\
\hline Räkälä (Рякяля) & 23 & 7 & - \\
\hline Väike-Rорми (Малая Ропша) & 22 & 13 & - \\
\hline Uus-Vüӧdеrтаа (Новая Фёдоровка) & 18 & 66 & 20 \\
\hline Karstala (Каростель) & 17 & - & - \\
\hline Kullaküla (Мертвицы) & 1 & 134 & 6 \\
\hline Kokku & $\mathbf{1 0 2 7}$ & $\mathbf{5 8 5}$ & $\mathbf{4 7}$ \\
\hline
\end{tabular}

1 Ruumi kokkuhoiu mõttes pole kirjutises viidatud nimepanekuprotokolli lehtedele, vaid on piirdutud perekonnanime ette kirjutatud külanimelühendiga, mille järgi saab arhiiviallika kirjele lisatud loendist teada vajaliku küla kohta käivate protokollide lehenumbrid. Külanimesid kirjutatakse eri allikates isemoodi. 
Osaliselt saab nende saamislugu selgitada. Näiteks osa Väiküla nimesid saab seostada vene keele üldsõnadega, nagu nt nime Kalašnikov sõnaga калачник калашник 'kalatšide küpsetaja või müüja'. Aleksei Krjukov (2007: 128) nimetab seda nime isuritel kunstlikuks vene nimeks, sest see ei kajasta kohalikku tegevusala. Purvinski on ilmselt poola nimi (õigemini Purwiński), mistõttu see pärineb isuristunud poolakalt (vt eespool).

Väike osa Eesti-Ingeri venepäraseid perekonnanimesid oli läänemeresoome algupära. Krjukovi (2007: 127, 139) arvates võiksid selliste hulka kuuluda Buštšin (<? sm pussi), Pillin (<Pillin omat), Pjassin $(<$ Pässin omat), Timoivov (< isikunimi Timoi) jt.

\section{4. (Uute) perekonnanimede panekust}

Eesti Vabariigi alguses loodi uute perekonnanimede võtmiseks või seniste muutmiseks seaduslik alus. 17. detsembril 1919 seadustati Eesti kodanikel halvakõlaliste ja -sisuliste või võõrapärase kõlaga perekonnanimede muutmise võimalus (Seadus 1920). 4. aprillil 1921 võttis Eesti Vabariigi valitsus vastu seaduse „Petserimaa ja Naroowa taguste waldade elanikkude perekonnanimede kohta“, milles kohustati nende valdade kodanikke, kellel on üksnes ees- ja isanimi, võtma perekonnanime, mis kinnistuks ka abikaasale ja kõigile alla 18aastastele ning nõusoleku korral ka täiskasvanud lastele. Lisaks anti võimalus võtta võõrapärase nime (,kelle nimedel wõõrakeelne kõla on“) asemele uus (Seadus 1921).

Sama aasta 29. juunil anti välja määrus asjaomase seaduse rakendamise kohta (Määrus 1921). Selles nähti ette luua kolmeliikmelised komisjonid, mille koosseisu pidid kuuluma esimehena siseministeeriumi esindaja, vallavanem või selle abi ning vallasekretär. Samas määruses oli kirjas komisjoni tööülesanded, perekonnapea kohustused perekonnanime saamisel, samuti meetmed nende vastu, kes pole määratud ajaks perekonnanime võtnud.

Nimepaneku põhimõtetes lepiti täpsemalt kokku juba enne Setumaal tegutsema asumist. 19. septembril 1921 kehtestati nimepanekukomisjonide ühisistungil järgmised juhised: 1) igaüks valigu perekonnanimi oma emakeele sõnade hulgast, 2) valla piirkonnas olgu igal perekonnal (v.a lähisugulased) erinev perekonnanimi, 3) perekonnanimed olgu 
võimalikult lühikesed ja hea kõlaga, 4) jäetagu võtmata Eestis väga sagedasti esinevad või tuntud isikute perekonnanimed (Sommer 1922a). Uue perekonnanime panemise põhjuseks võis olla ka asjaolu, et külas elas mitu samanimelist peret, kes ei olnud omavahel (enam) sugulased; samasugused nimed võisid raskendada ametlikku asjaajamist. Näiteks elas Väikülas toona üle tosina Reškini-nimelise perekonna rohkem kui poolesaja liikmega, ka Jemeljanoveid oli viis perekonda (Emel'anov 2011: 354).

Perekonnanimede panekul sai oluliseks abivahendiks valimik „15 000 uut sugunime“ (VTU), mis valmis Akadeemilise Emakeele Seltsi kui nimede eestistamise käivitaja hoogsa tegutsemise tulemusel valminud nimede vahetamist õhutava, seletusi ja näpunäiteid jagava albumi „Eestlasele eesti nimi““(EEN) lisana (vt lähemalt Henno 2001).

Petserimaal kestis nimepanek 1921. aasta lõpuni. Samal aastal moodustati Narva-taguste valdade rahvale perekonnanimede panekuks kolm komisjoni, mille esimeheks määrati Narva ja Karjati vallas Samuel Sommer ning Kose vallas Villem Ernits (Nurka 2010: 13). Protokollide järgi tegutses kõigis kolmes vallas esimehena küll ainult Sommer (EAA.5433.1.8; EAA.5433.1.9). 1922. aasta jaanuaris käis Sommer kõikides vallavalitsustes, jagades kohalikele komisjoniliikmetele (vallavanem või selle abi ja vallasekretär) juhtnööre perekonnanimede panekuks. Kõigepealt tuli igas vallas koostada nimekiri isikutest, kellel polnud püsivat perekonnanime või kes soovis seda muuta. Rahvast pidi aegsasti teavitama, et neil jääks endale sobiva nime valimiseks rohkem aega (Nurka 2010: 22-23). Nimepanek ei läinud nõnda libedalt, nagu lühidalt mainib Kati Nurka (2010: 26). Boriss Jemeljanovi teosest selgub, et Narva vallas, mille keskus asus toona Väikülas Ivan Hitrovi tühjas majas, oli rahvas sinna 4. veebruaril 1922 kella 11-ks kokku kutsutud ilma põhjust teatamata, mistõttu hädapärast 100 inimest mahutav maja kihanud kui ,ülesärritatud herilasepesa“ (Emel'anov 2011: 133-136).

Koosoleku avas väikese hilinemisega vallavanem Konstantin Reškin ja sõna sai Samuel Sommer, kes teatas eesti keeles, et Eesti Vabariigi valitsuse määruse kohaselt on Petserimaa ja Narvataguse perekonnanimede korrastamiseks loodud riiklik komisjon. Sommer luges ette asjakohased dokumendid ning ütles seejärel, et sobiva nime valimiseks antakse veidi aega. Kohalikud kooliõpetajad Andrei Tšuvirin ja Aleksandr Jakovlev protesteerisid nimepaneku vastu, väites, et Väikülas on perekonnanimed 
juba ammu olemas. Boriss Jemeljanov kirjutas selle kohta järgmist (Emel'anov 2011: 136) ${ }^{2}$ :

„Samuel Sommer ei jäänud nende esinemisega sugugi rahule. Ta läks isegi endast välja ja lausus ägeduses, et ta näeb enda ees mässajate kampa. Ta lisas, et Väiküla elanikud pole mingid venelased, ja seepärast ei saa nad, isurid, vere poolest eesti rahva vennad, kanda võõra kõlaga nimesid, ning kas nad tahavad või ei taha, antakse neile kõigile uued perekonnanimed kas või sundkorras, ja ei mingil juhul vene nimesid. Edasi tuletas Sommer õpetajatele Tšuvirinile ja Jakovlevile meelde, et nad on riigiteenistujad ja neile on täiesti mõeldamatu astuda valitsuse otsuse vastu. Ühtlasi andis ta mõista, et kuigi Eesti on territooriumi poolest väike riik, leidub mässajate jaoks ikkagi „kaugeid paiku“.

Selline asjade käik halvas talupoegade tahte, olid nad ju liiga inertsed, tumedad, harimatud ja organiseerimatud selleks, et üksmeelselt kogukonnaga seista oma vanaisadelt ja vanavanaisadelt saadud perekonnanimede allesjätmise eest.

Ja nad andsid alla.“

Algas nimepanek, mis kestis õhtuni. Perekonnanime jätsid endiseks vaid eespool mainitud kooliõpetajad (peale nende ka vadja päritolu kooliõpetaja Dmitri Tsvetkov), vallavanem, kingsepp ja hobusekarjus. Nagu mainib Jemeljanov, siis uued perekonnanimed ei juurdunud: isegi pool sajandit hiljem kasutas külarahvas omavahel suheldes endisi venepäraseid perekonnanimesid (Emel'anov 2011: 139).

Asjaomane komisjon tegutses Narvataguse külades põhiliselt 1922. aastal, vaid üksikjuhtudel jätkus töö ka järgmisel aastal. Perekonnanimede panek protokolliti ja igale kodanikule alates 15. eluaastast anti tunnistus nime võtmise või muutmise kohta (Sommer 1923a). Nimepanekukomisjon edendas ka ühiskondlikku elu. Sommeri ja Ernitsa algatusel rajati EestiIngeris haridusseltse, karskusühinguid ja iga õppeasutuse juurde asutati pühapäevakool. Karskuspropagandat tegi peamiselt Ernits (vt Sommer 1922b, 1923b).

Sommeri (1923a) andmeil võtsid Narva vallas uue perekonnanime 949 ingerlast ja 67 venelast ning oma nime muutsid 78 ingerlast ja 19 eestlast. Soomlastel ja eestlastel olid enamasti sobivad perekonnanimed olemas,

\footnotetext{
2 Enn Ernitsa tõlge.
} 
mistõttu uute nimede saajad olid isurid; nime soovisid muuta mõned soomlased ja eestlased. Laias laastus on Sommeri esitatud arv kooskõlas Ernitsa loendustulemustega. Sommer (1923b) avaldas ka arvandmed Eesti-Ingeris võetud ja vahetatud perekonnanimede kohta (vt tabel 2). Tema statistiliste tabelite koostamise alused pole teada. Näiteks pole mõistetav, kuidas ta eristas eesti, soome ja isuri (ingeri) nimesid, sest eriti viimastel pole sageli võimalik vahet teha, lisaks langevad nad kohati kokku eesti omadega. Selle tõttu käsitletakse artiklis uusi perekonnanimesid kolme eraldi rühmana: eestipärased, soome-isuripärased ning muud algupära nimed.

Tabel 2. Eesti-Ingeris võetud ja vahetatud perekonnanimede arv

\begin{tabular}{|l|r|r|r|r|c|}
\hline Perekonnanimed & Eesti & Isuri & Soome & Vene & Kokku \\
\hline Võetud & 175 & 46 & 15 & 131 & 367 \\
\hline Muudetud & 6 & 5 & 8 & - & 19 \\
\hline Kokku & $\mathbf{1 8 1}$ & $\mathbf{5 1}$ & $\mathbf{2 3}$ & $\mathbf{1 3 1}$ & $\mathbf{3 8 6}$ \\
\hline
\end{tabular}

Eeltoodust ilmneb, et nimepanekuseadus andis ainult võimaluse muuta oma nime, ent tegevust alustanud nimepanekukomisjon tegi vene nimedega isuritele nimevahetamise kohustuslikuks, kusjuures enamiku (71\%) uutest läänemeresoome perekonnanimedest moodustasid eestipärased nimed. Seevastu venelased said vene nimed.

\section{Eestipärased perekonnanimed}

Eesti-Ingeri uute perekonnanimede seas on eestipäraseid kõige rohkem. Suur osa nimesid pärineb VTUst. Tähenduse järgi seondub enim nimesid loodusega, neist domineerivad nominatiivsed taimede või nende osade nimetused: Saa, Väi Kask, Saa Kuusk, Van Käbi, Kal, Saa Leht, Han Lepp, Saa Lill, Väi Mänd, Räk Paju, Väi Sammal (VTU: 54), Kul? Sirel (vrd Sireli, VTU: 55), Van Tamm, Kal Vaher ja Van Õun. Genitiivne perekonnanimi on vaid Väi Roosi ja ehk ka Van Pihli (vrd pihl 'pihlakas', pihline 'pihlakane', VMS II: 199). Roosi pole saadud eesnimest, mida kinnitavad Roosi-tüvelised liitsõnad. Liitsõnalised ongi valdavalt Roosi- ja Lilleosist sisaldavad nimed, nagu Han, Kal Lillepuu, V-Rop Lillepärg, Väi Roosilill, Kal Roosioks ja Van, Väi Roosipuu, lisaks veel Van Öunapuu. Liite - as kasutamine on tänapäevasest erinev ja vajaks eraldi uurimist; ühelt poolt on registreeritud Väi Maasik, Väi Pihlak ja Kar Toom (vrd 
Toome, VTU: 59), teisalt aga Jalakas, Kadakas, Van Maasikas, Kal Pihlakas, Pohlakas (vrd pohlakas 'pohl', VMS II: 229), Kal Toomingas ja Van Toomikas (vrd Toomik, VTU: 59; toomik 'toomingas', VMS II: 525). Murdeline nimekuju on kahtlemata VTU soovitusnimi Han Vahter (VTU: 63; VMS II: 629). Taimenimetustest lähtunud perekonnanimede hulgas on valdavad puunimetused. Loodusnimetustega seondub veel Väi Kivi.

Arvukuselt teisele kohale jäävad looduskogumite või -kohtade nimetustest saadud perekonnanimed. Neid on üle kolmandiku võrra vähem kui taimenimetustest lähtuvaid, nt Van Allikas, Kar Järv, Väi Kaasik, Uusküla, Van, Kalju, Kal Kivistik, Räk Kuusik, Van Lepik, Saa Meri, Uusküla, Van Mets, Saa, Van Mägi, Väi Põld, U-Vüö Rand ja Van Salu. Murdesõnast pärineb Väi Vahtrik (vrd vahtrik' vahtramets', VMS II: 630). Liitsõnalised on järelosist -soo sisaldavad Väi Kivisoo, Kar Marjasoo (vrd VTU: 35 Marjassoo) ja Kar Suursoo (VTU: 56; Emel'anov 2011: 353 annab ekslikult Sursoho, selles teoses on teisigi nimevääratusi). Suursoo on saadud endisest perekonnanimest Sursov ( $<$ ingerisoome Suursoho); nimepanekuprotokolli allkirjastas Peeter Madise poeg kirillitsas Surso kujul. See osutab algse eesti nime venepärastumisele. Omastavalised on Saa Liiva ja Väi Metsa. Liiteta on Väi Allik.

Veidi vähem kui looduskogumite nimetusi on uuteks perekonnanimedeks loomanimetusi (sh kalade, lindude, imetajate ja erandina ka paari putukaliigi nimetused): Väi Kala, Väi Karu, Saa Kaur, Väi Kotkas, Saa, Van Luik (<Lukina; vrd Luige, VTU: 33), Van Luts, Saa Lõhe, Saa Part, Kal Siig (VTU: 54), Väi Sääsk, Kar Tetre, Van Tui, Kal, U-Vüö Tuvi. Neist Tetre (vrd Kuusalu tetretähtiline, Lüganuse tetretäppiline 'tedretähniline' ja ingerisoome Tetri) ja Tui (vrd tui 'tuvi') näikse olevat murdelist algupära (VMS II: 502, 570). Dolgaja Niiva, Väi Põdra (< Patrakejev; ka VTU: 49) on vormi poolest omastavaline perekonnanimi, ent Väi Pässi ja Han Kotka (viimane pole igatahes isuri keelest, milles 'kotkas' on kokko, IMS: 186) puhul on raske öelda, kas see on eesti nime genitiivne kuju või isurisoome nominatiiv. Nime Pässi puhul tuleks ehk lähtuda tõigast, et ta on saadud vene nimest Pässina (tänapäevaselt translitereerituna Pjassina), mis omakorda lähtub, nagu eespool mainitud, läänemeresoome sõnast. as-liiteta on Kal Kajak (VTU: 13).

Huvipakkuv on Väi Mägar (< Makar; vrd mägar 'mingi putukas; mäger'; VMS I: 54), mis leidub ka soovitatud perekonnanimede hulgas (VTU: 38). Jemeljanov mainis Väikülas üht Sambla perekonna järeltulijat, 
kes võttis endale nimeks Merikotkas (pärit VTU: 36), ent nimepanekuprotokollis on see maha kriipsutatud (Emel'anov 2011: 136, 352, 434; EAA 5433.1.5. L 76). Kas seda nime taotleti siis hiljem uuesti? Vanakülas oli ühe perekonna nimeks registreeritud Poder, mis pole ei eesti ega isurisoome nimi. Tegu on eesti sõna soome- või isuripärase hääldusega. Hiljem ongi võetud kasutusele Põder.

Veelgi vähem on mitmesuguste esemete nimetustega sarnanevaid perekonnanimesid, nagu Kal Kangas, Väi Kannel, Väi Kivala (vrd Kivalo, VTU: 21; kival 'sikuska vars', VMS I: 238), Väi Kubik (<Gubikov), Väi Lennuk (vrd Lennok, VTU: 31; seda on kasutatud ka Karjati vallas), Väi Pill, Väi Puur, Väi Raud, Kal Rull, Saa Sirp (VTU: 55) ja Kal, Väi Veski. Omastavaliste perekonnanimedena võib käsitada nimesid Väi Kuuli ja Kuulu (< Gulin; Jemeljanov $u$-list nime ei maini), Väi Pilli $(<$ Pillin; vrd ka Pilliaasa jt, VTU: 47), Väi Pussi (<Buštšin) ja Van Saia, mis kõik olid algselt soomepärased.

Teisi tähendusrühmi leidub Eesti-Ingeri uute perekonnanimede seas veel vähem. Kohanimedega ühtivad Väi Rootsi, Väi Sakala (< Sokolov), Väi Tuudar (vrd kohanimi Tuutari) ja Väi Viru (VTU: 65). Loodusnähtusi väljendavad Kar Kaja, Väi Lain (ka VTU: 29; 1938. aastal muudeti Laine'ks, Emel'anov 2011: 139), Väi Lumi (ka is), Van Tuisk (vrd Tuisu, VTU: 59); elukutset Väi Kalamees, Väi Kalanik (< Kalašnikov; vrd Kodavere kalanik 'kalur', VMS I: 161; vdj kalanikka 'kalamees; kalakaupmees', VKS: 367-368), Kal Kangur, Han Kapral, Väi Leitnant, Väi Timmer (Vaivara timmer 'puusepp', VMS II: 511; vrd Timbre, VTU: 58); omadust Väi Rikas, Väi Talts (vrd talts 'taltsas', VMS II: 484), Väi Valge; eesnime Väi Mark (vaevalt et võõrapellatiiv), Väi Markus, Väi Vilma; tuntud isikute perekonnanimesid Saa Laidoner ja Kar Luterus ( $<$ Ljutrus-Ljuters; vrd Luther); vaimolendeid Van Kolli (< koll; vrd ka sm kolli 'suguti'), Väi Päär (vrd päär 'kratt', VMS II: 289; Päärumäe, VTU: 49).

Esineb perekonnanimesid, mida on alusnime järgi ühel või teisel põhjusel raske rühmitada. Neist osa saab pidada eesti sõnadeks, nagu Saa Kalm, Väi Kurs (vrd kurss 'suund; latt; kurt', VMS I: 322), Kal Soiu (vrd soiguma), Kal Sork (vrd sork 'sõrg, hark; sörk; rott', VMS II: 434; vrd Sorgu VTU: 56), Väi Sulp (vrd sulp 'loomasööt; puderjas mass'; vt ka osa 6) ja Van Vader. Nime Van Lemming saab ühendada samakõlalise murdesõnaga tähenduses 'laps' (VTU: 31; VMS I: 425). Ülejäänud näikse eesti keele seisukohalt olevat tehistuletised, nagu Saa Kanger, Kar Kudep, 
V-Rop Naabel (ka VTU: 39, seepärast on viimane paigutatud eestipäraste nimede sekka; vrd siiski sks Nabel 'naba'), Kar Sildus (vrd siiski kohanimi Sildusniit, Saar 2009: 72), Van Siller, Saa Sõstrand, Kal Vaimel ja Väi Venela (VTU: 64). Huvitaval kombel esineb nende hulgas vaid kaks VTU nime. Suuremalt jaolt isuri elanikkonnaga Vanaküla ainuke eestlane Aleksander Kiibats (vrd kiibats 'kõhn', VMS I: 216, samuti ingerisoome Kipatsa) võttis endale uueks perekonnanimeks Vennane (vt ka osa 6).

\section{Soome- ja isuripärased perekonnanimed}

Soome-isuripärastest perekonnanimedest võeti kõige sagedamini loomanimetustest lähtuvaid perekonnanimesid. Nende seas on vähi-, kala- ja eriti linnunimetusi, kuid huvitaval kombel puuduvad imetajate omad: Kar, Saa Habukka (varasemast perekonnanimest Habukin; vrd vps habuk 'kull', kuid sm, is haukka < *haßukka, IMS: 50; IKH: 32), Väi Hauki (vrd sm, is hauki 'haug'), Van Joutse (vrd sm, is joutsen 'luik', IMS: 107), Han Kajava (vrd sm 'kajakas', is kajjava jt, IMS: 125), Kal Krabu (vrd is Soikkola kraBu 'vähk', IMS: 204; sm Krapu 'Vähi tähtkuju'), Kul Lohi (vrd sm, is lohi 'lõhi', IMS: 272), Kar Metso (vrd is Alam-Lauga metso 'metsis', IMS: 307), Han Sirkkune (vrd is sirkku 'varblane', IMS: 528; vrd sm Sirkka, SSN: 731), Van Varkki 'tõmmuvaeras', Kal Varonen (vrd sm varoi 'vares', SSN: 841). Tuleks silmas pidada, et algselt oi-lõpulised sõnad (nt sm kirjakeele ja Soikkola murde metsoi) esinevad $o$-listena isuri keele Alam-Lauga murdes, mille alale jäävad Eesti-Ingeri külad, ning ingerisoome murrakutes, samuti vadja keeles (Laanest 1966: 87).

$K r a b u$ sõnasisene $b$ võib olla sugenenud nimekomisjoni eestipoolse mõju tagajärjel, sest Alam-Lauga murdes on, nagu soome keeleski, sõnasisesed klusiilid erinevalt teistest isuri murretest tugevad (Laanest 1966: 20-21). Nii saab ka nime Hauki (samuti Joki, vt allpool) puhul lähtuda nii soome kui ka isuri keelest.

Eelmise rühmaga võrreldes on kolmandiku võrra vähem taimede või nende osade nimetustega seonduvaid perekonnanimesid, nagu Van Koivune (vrd sm, is koivu 'kask'; IMS: 185), Van Lehtine (vrd sm, is lehti 'leht', IMS: 257-258)33, Kal Mansik (lõpu poolest eestipärane; vrd sm mansikka, is mantšikka mantsikka 'maasikas'), Han Pajune (VTU: 45;

3 Esialgu sai selle perekonnanime tuntud vadja keelejuhi Darja Lehti (varem Loginov) pere Vanakülast. 
vrd ee, sm, is paju, IMS: 377), Väi Pähen, Han Tammi (vrd sm, is tammi 'tamm : tamme'; vrd siiski ka ee tamm : tammi). Nimekuju Pähen puhul võidi eeskuju saada eesti soovitusliku perekonnanime Pähensaare algusosast (VTU: 49), vrd ee pähes, pähkes (VMS II: 282), sm pähkinä, is päähkänä 'pähkel' (IMS: 453).

Eelmise rühmaga võrdselt on looduskogumeid ja -kohti tähistavatest sõnadest lähtuvaid perekonnanimesid, nagu Van Ahone (VTU: 2; vrd sm aho 'sööt : söödi; lagendik' ja Ahonen, SSN: 261), Väi Joki (< is, sm joki 'jõgi'), Räk Kosteinsalo (vrd sm Kostamo, SSN: 428), Muurmetsä (vrd sm Muurijoki, Muurimäki, SSN: 541), Van Pekkinen (Soomes osaliselt sõnast pekki 'oja', osaliselt nimest Pekka, SSN: 604) ja Van Tammikko (< sm tammikko 'tammik'; vrd is tammizikko, IMS: 572). Soome Joki muudeti 1938. aastal eestipäraseks nimeks Jõgi (Emel'anov 2011: 139). Kosteinsalo panekule võis kaasa aidata eesti soovitusliku Kostsaare algusosa (VTU: 23). Siia rühma võib paigutada ka Kul Kaulio, mida peetakse sõna kaula 'kael' tuletiseks tähenduses 'ümbrusest kitsam või madalam koht maastikul' (SSN: 389).

Esemete ja materjalide nimetusi kajastavad Van Kauppa (vrd sm, is kauppa 'kaup', IMS: 146), Van Padanen (vrd sm, is Alam-Lauga pata, is Soikkola paDa 'pada', Laanest 1966: 20), Kar Silkki (vrd sm silkki 'siid', kuid is sulkku, IMS: 550), Kar Säkki (< Säkkina, vrd sm, is säkki 'kott : koti'). Võimalik, et Padanen (vrd ka ingerisoome Väi Patanen) on tekkinud nimekomisjoni liikmete mõjul (nagu Krabu).

Hüüd- ja eesnimedega saab ühendusse viia perekonnanimed Han Pesone (vrd sm Pesonen < isikunimi, SSN: 610), Väi Peto (Emel'anov 2011: 355; vrd is Pet'aa, IMS: 403) ja Väi Timmo (< Timojev). Peto nime võtnud Tšuvirinid pärinesid Pjotriks ristitud vendadest (Emel'anov 2011: 355). Kohanimede ja rahvusenimetustega liituvad Väi Hämäläinen ('hämelane'; ka SSN: 330), Kar Suomalainen ('soomlane') ja Räkälä (koduküla järgi).

Mõne perekonnanime klassifitseerimine on erinevatel põhjustel raskendatud. Kal Elone oli XX sajandi alguses rootsipäraste nimede soomestamisel soositumaid perekonnanimesid, mis esines kujul Elo, Elonen jt, kusjuures sm elo tähendab 'elu; küps vili' (vrd ka is elo 'elu', SSN: 277). Tõsi küll, esialgu pandi Eesti-Ingeris perekonnale nimeks Ilonen (vrd sm, is ilo 'rõõm', IMS: 92), mida hiljem muudeti ilmselt populaarsuse tõttu Soomes. Rühmitamata jääb ka V-Rop Pelkonen (ka SSN: 604). Nime 
Van Vennane (vt osa 5) puhul pole selge, kas see pärineb eesti (vrd *vennane $<$ vend) või isuri keelest (vrd vennäin 'niine-', IMS: 653). Ainuke loodusnähtuse nimetusest saadud perekonnanimi on U-Vüö Myrsky (vrd sm myrsky; vrd is mürskü 'torm', IMS: 324). Otsetõlkeline on Väi Hauki, vrd sm hauki 'haug' (< Štšukin, vrd щука 'haug').

Nagu esitatust ilmneb, võttis osa elanikke soomepärase nen-liitega, teised aga eesti- resp. isuripärase ne-liitega perekonnanime. Erinevalt teistest murretest ei esine Alam-Lauga murdes nen-lõpulisi sõnu (Alam-Lauga punaine 'punane', venäläine 'venelane'); nen-sõnades esineb $n$-hääliku apokoopi ka ingerisoome murrakutes ja vadja keeles (Laanest 1966: 65).

Huvitav on eestipäraste perekonnanimede seas mainitud Sulp (vt osa 5), mille Jemeljanov avaldas kujul Шульпо ning mille kohta nimesaanu andis protokollis allkirja Шульпь (Emel'anov 2011: 353; ЕAA 5433.1.5. L 83). Võimalik, et $\check{s}$-line variant on tekkinud is $\check{s} u l p p i a$ 'sulistada, pladistada' (IMS: 550) mõjul.

Järgnevalt soome perekonnanimedest, mis nende kandjatele ühel või teisel põhjusel ei meeldinud. Need on Kul Harakka (sm 'harakas'), Han Hussu (tähendus teadmata) ${ }^{4}$, Han Mustonen, Van Pekki, Kal Pohjalainen (vrd sm pohjalainen 'põhjamaalane'), V-Rop Pukonen (<Puukkonen; vrd sm puukko 'pussnuga') ja Kal Voipä ('võipea'). Need vahetati peamiselt kas soome või eesti nimede vastu, vaid ühel juhul valiti saksapärane nimi Auer (Han). Ainult Pekki piirdus oma perekonnanime täiendamisega liite -nen abil (Pekkinen), ülejäänud eelistasid muutüvelisi soome perekonnanimesid, millest oli juttu juba eespool: Ilonen ( $>$ Elone), Kosteinsalo, Lohi, Mansik, Pelkonen, Pesone, Sirkkune ja Varonen. Vaid üks perekond (Voipä) võttis soome nime Ilonen, kolm perekonda otsustasid eesti perekonnanimede Jalakas, Kangur ja Leht kasuks; eestipärase nime Lillepärg sai ka V-Rop Pukonen (vt ka osa 5).

\section{Muud perekonnanimed}

Peale uute eesti- ja soome-isuripäraste perekonnanimede leidub veel nimesid, millel on sarnasust vene keele ning erandjuhul ka mõne muu keele sõnadega. Selliste hulka kuuluvad eriti need perekonnanimed, mis on moodustatud endiste vene perekonnanimede põhjal, nagu Hitro, Hovaski,

4 Husso esineb tänapäeva Soomes perekonnanimena üle poolel tuhandel isikul, samuti käibib samakujulise toponüümina (Husso). 
Kalasnik jt (vt osa 8). Seevastu osal võõrapärastel perekonnanimedel puudub side endiste nimedega: Väi Kalina (vrd vn калина 'lodjapuu'), Saa Munti, Väi Voro (vaevalt et sm voro 'varas' < vn вор 'varas'), Saa Ukleika (vrd vn уклейка 'viidikas'). Perekonnanimi Väi Ura, mis sarnaneb häälikuliselt ka soome sõnaga ura 'uure; karjäär', on teadupoolest saadud hüüdnimest (Emel'anov 2011: 355) ja seondub ehk vene hüüdsõnaga ypa 'hurraa'. Väi Buikis ei erine oluliselt endisest läti perekonnanimest Buiķis (vrd buk,is 'nõu soola peenestamiseks ja säilitamiseks'?, ME: 347). Häälikuliselt eestipärasena tunduv Kul Kirilavits lähtub venestunud poolaka perekonnanimest Kirilovitšs (poola Kiriłowicz). Han Auer näib pärinevat saksa keelest (vrd sks Auerhahn 'metsisekukk' ja Auerochs 'ürgveis' algusosa, mis esineb perekonnanimena ka mujal). Alamsaksa keelega saab ehk ühendada Dolgaja Niiva nime Beek (vrd beek'oja', KPW: 10).

\section{Vene perekonnanimede asendamise võtetest}

Mille vastu venepärased nimed vahetati? Enamik perekondi võttis täiesti uue läänemeresoome nime, nt Väi Ahonen (varem Krapov), Mägi (endine Habukin), Vaher (varem Jegorov), Saa Kask, Kal Siig jne. Sageli (eriti Väikülas) moodustati uusi perekonnanimesid otse vene nimede põhjal.

Osa isikuid sai sobiliku perekonnanime vene nime kohendamise teel, kusjuures ära jäeti lõpu $-n$ ja -(o)v, sõnaalguline heliline häälik ning võõrtähed, nt Väi Hitro < Hitrov (vrd xumpbiŭ 'kaval'), Väi Hovaski< Hovaskin, Väi Kalasnik< Kalašnikov, Kar Pahval < Bahvalov, Väi Pampus < Pampussov, Väi Reski ja Räski < Reškin, Väi Suveri < Tšuvirin. Seevastu osal uutel perekonnanimedel, nagu eespool mainitud Kalina, Munti jt, puudub side endiste nimedega.

Üle tosina uue perekonnanime moodustati vene nimekuju eestipärastamise, harvem isuri- või soomepärastamise teel, mistõttu uus ja vana nimi on kõlaliselt sarnased, nt Väi Kuuli $<$ Gulin, Väi Kalamees ja Väi Kalanik< Kalašnikov, Han Kapral < Kapralov, Väi Kubik< Gubikov, Saa Luik < Lukina, Kar Marjasoo < Morozov, Väi Pohlakas $<$ Poljakova, Väi Põdra $<$ Patrakejev, Väi Sakala $<$ Sokolov, Väi Sammal $<$ Samsonov, Väi Terkki $<$ Derkin. Seevastu uute perekonnanimede Saa Habukka $(<H a b u$ kin), Väi Pilli (< Pillin), Väi Pussi (< Buštšin), Väi Pässi (<Pässina), Kar Silkki $(<$ Silkina), Kar Säkki $(<$ Säkkina), Väi Timmo $(<$ Timojev) alusnimed olidki läänemeresoome algupära. Nimepanekuprotokollide 
järgi elas muide Väikülas peale kolme Timojevite perekonna ka üks perekond Timoivoveid; Jemeljanovi loendites (Emel'anov 2011) esineb millegipärast üksnes viimane nimi ning seegi pärineb eesnimest Timoi (vt IMS: 586). Pole võimatu, et Väiküla vene perekonnanimedest on tuletatud ka Maasik < Menštšikova (is ja sm man(t)sikka mantšikka 'maasikas' vahendusel), Rikas < Grigorjev ja Venela $<$ Jemeljanov.

Otsetõlkelised on Väi Hauki < Shtshukina (Šť̌ukina) (vrd vn щукa 'haug') ja Valge < Belov (vrd vn бельй 'valge'). Selline on ilmselt ka Väi Pähen, mis võib olla tekkinud Reškini nime seostamisel vene apellatiiviga орешек 'pähklike'. Väi Mark ja Markus näivad pärinevat nimesaajate isanimest Mark, Väi Mägar aga isanimest Makar (nimepanekuprotokollis esialgu $k$-ga, hiljem kirjutatud $g$-ga).

\section{Lõpetuseks}

Eesti-Ingeri etnilise olukorra uurimine on keerukas. Perekonnanimede vallas muutus see nimepaneku ja -vahetusega veelgi keerukamaks, sest isurid said enamasti kas eesti (enamjaolt) või soome nime, vaid üksikud jäid endise venepärase nime juurde. Eestlastel ja soomlastel olid perekonnanimed olemas. Nad vahetasid välja vaid neile vastumeelsed nimed, kusjuures mõned eestlased muutsid senised venepärased perekonnanimed eestipäraseks. Soomlased võtsid enamasti uued soome, mõnel juhul ka eesti nimed.

Varem vene perekonnanimesid kandnute uued nimed kujutavad endast eesti või isuri ja soome apellatiive, eesti tehisnimesid, endiste perekonnanimede tõlkeid või moondeid. Eestipäraste perekonnanimede allikaks on paljudel juhtudel olnud VTU, ent selle võimaluste kasutamist Eesti-Ingeris võib hinnata siiski tagasihoidlikuks.

Nii eesti- kui ka soome-isuripärased perekonnanimed kajastavad suuremalt jaolt loodust, sh taimi, loomi, looduskogumeid ja -nähtusi. Eri keelte nimede jagunemist ei tasu statistiliselt võrrelda, sest muudetud soome-isuri nimesid on suhteliselt vähe ning neid on võetud sageli teistel motiividel kui eestipäraseid nimesid. 


\section{Külanimede lühendid}

Han - Hannika; Kal - Kallivere; Kar - Karstala; Kul - Kullaküla; Räk - Räkälä;

Saar - Saarküla; U-Vüö - Uus-Vüödermaa; Van - Vanaküla; V-Rop - VäikeRopsu; Väi - Väiküla

\section{Arhiivimaterjalid}

EAA 5433.1.5. Narva valla elanike perekonnanimede panemise protokollid. 1921-1922. Külad tähestikjärjestuses ning protokollilehed: Dolgaja Niiva 99-103; Hannika 49-51; Kallivere 63-66, 105; Karstala 67-70, 73-74; Komarovka 96-98; Kullaküla 55-56; Popovka 89-90; Räkälä 61-62; Saarküla 71-74; Zahhonje 94-95; Zaretšje 91-93; Uusküla 104; UusVüödermaa 87-88; Vanaküla 57-60; Väike-Ropsu 52-54; Väiküla 75-86.

EAA.5433.1.8. Piiri (Kose) valla elanike perekonnanimede panemise protokollid. 1921-1923.

EAA.5433.1.9. Raja (Skarjatina) valla elanike perekonnanimede panemise protokollid. 1921-1922.

\section{Kirjandus}

EEN = Eestlasele eesti nimi. 1921. (= Akadeemilise Emakeele Seltsi toimetused 2.) Tartu: Akadeemiline Emakeele Selts.

Emel'anov 2011 = Борис К. Емельянов (Йыги). Пласты истории села Венкуль, сиречь Наровского, с незапамятных времен по настоящее время. Санкт-Петербург: Реноме.

Ernits, Enn 2009. Vadja haritlane Dmitri Tsvetkov. Tartu: Eesti Kirjandusmuuseumi Teaduskirjastus.

Ernits, Villem 2013 (1922). Kirjad Eesti-Ingerist. - Villem Ernits. Noorpõlve ideaalid. Koost. Hando Runnel. Toim. Katre Ligi. (= Eesti mõttelugu 113.) Tartu: Ilmamaa, 244-253.

Ernits, Villem 2013 (1925). Eesti-Ingeri eesti-soome kultuurisünteesi katselavana. - Villem Ernits. Noorpõlve ideaalid. Koost. Hando Runnel. Toim. Katre Ligi. (= Eesti mõttelugu 113.) Tartu: Ilmamaa, 254-257.

Henno, Kairit 2001. Emakeele Selts nimede eestistamise käivitajana. - Keel ja Kirjandus 2, 73-91.

IKH $=$ Arvo Laanest. Isuri keele Hevaha murde sõnastik. 1997. Tallinn: Eesti Keele Instituut.

IMS = Inkeroismurteiden sanakirja. 1971. Toim. R. E. Nirvi. (= Lexica Societatis Fenno-Ugricae XVIII.) Helsinki: Suomalais-Ugrilainen Seura. 
Koreinik, Kadri, Tõnu Tender 2014. Eesti keeltest rahvaloendustel. - Emakeele Seltsi aastaraamat 59 (2013). Peatoim. Mati Erelt. Tallinn: Teaduste Akadeemia Kirjastus, 77-102. http://dx.doi.org/10.3176/esa59.04.

KPW - Johannes Sass. Kleines plattdeutsches Wörterbuch mit Regeln für die plattdeutsche Rechtschreibung. 17. Auflage, 1997. Wachholtz Verlag.

Krjukov 2007 = Алексей В. Крюков. О фамилиях води и ижор. - Финноугорская топонимия в ареальном аспекте. Материалы научного симпозиума. Петрозаводск, 122-142.

Laanest 1966 = Арво Лаанест. Ижорские диалекты. Лингвогеографическое исследование. Таллин: Институт языка и литературы.

$\mathbf{M E}=\mathrm{K}$. Mülenbacha Latviešu valodas vārdnīca. K. Mühlenbachs Lettischdeutsches Wörterbuch. 1, 1923. Rediǵējis, papildinājis, turpinājis Jānis Endzelīns. Rīgā: Izdevusi Izglītîbas ministrija.

Määrus 1921 = Määrus Petserimaa ja Naroowa taguste waldade elanikkude perekonnanimede seaduse (,RT“. nr. 26 - 1921 a.) teostamise kohta. Riigi Teataja 58, 350-351.

Rosenberg, Tiit 2013. Maareformist Eesti Vabariigi Virumaa Narva-tagustes valdades 1920-1940. - Õpetatud Eesti Seltsi aastaraamat 2012. Peatoim. Heiki Valk. Tartu: Õpetatud Eesti Selts, 129-142.

Saar, Evar 2009. Võrumaa kohanimed. (= Tartu Ülikooli doktoritöid.) Tartu: Tartu Ülikooli Kirjastus.

Seadus $1920=$ Perekonnanime muutmise seadus. - Riigi Teataja 2/3, 15 .

Seadus 1921 = Seadus Petserimaa ja Naroowa taguste waldade perekonnanimede kohta. - Riigi Teataja 26, 163.

Sommer, Samuel 1922a. Perekonnanimede üle Petserimaal. - Postimees 8. II.

Sommer, Samuel 1922b $=-m$ - Kuidas meie Naroowa wallas perekonnanimede panemisel tegewad olime. - Postimees 25. II.

Sommer, Samuel 1923a. Perekonnanimede panemisest Naroowa tagustes waldades, Narwa-Jõesuus ja Narwas [1]. - Postimees 13. VIII.

Sommer, Samuel 1923b. Perekonnanimede panemisest Naroowa tagustes waldades, Narwa-Jõesuus ja Narwas [2]. - Postimees 14. VIII.

SSN = Suuri suomalainen nimikirja. 1985. Kustaa Vilkuna, Pirjo Mikkonen, Sirkka Paikkala. Helsinki: Suuri Suomalainen Kirjakerho.

VKS = Vadja keele sõnaraamat. Vad'd'aa tšeelee sõna-tširja. Словарь водского языка. 2013. 2., täiendatud ja parandatud trükk. Toim. Silja Grünberg. Tallinn: Eesti Keele Sihtasutus.

VMS = Väike murdesõnastik. I-II, 1982-1989. Toim. Valdek Pall. Tallinn: Valgus. VTU $=15.000$ uut sugunime (Lisa albumile „Eestlasele Eesti nimi“). 1921. (= Akadeemilise Emakeele Seltsi toimetused 4.) Tartu.

Üldrahvalugemise 1924 = 1922 a. üldrahvalugemise andmed, IV, Viru maakond. Tallinn: Riigi Statistika Keskbüroo. 


\section{Võrgumaterjalid}

Husso $=$ Husso: Sukunimi-info. http://www.tuomas.salste.net/suku/nimi/husso. html (30.12.2015).

Istorija = История появления фамилий. http://geno.ru/istoria-poyavleniafamilii/ (9.12.2015).

Nurka, Kati 2010. Perekonnanimede panek Petserimaal ja Narva-tagustes valdades 1921.-1923. aastal. Bakalaureusetöö. Juhendaja Aigi Rahi-Tamm. Tartu. http://www.eki.ee/nimeselts/txt/bo04282.pdf (20.04.2015).

Russkie familii = Русские фамилии. $\mathrm{http}: /$ kakzovut.ru/russkie-familii.html (19.12.2015). 


\title{
New family names in Estonian Ingria and their giving in 1922
}

\author{
ENN ERNITS
}

Estonian Ingria was a small part of the historical Ingria, which belonged to the Republic of Estonia from 1920-1946. Ingrians, Ingrian Finns, Estonians, Russians and a few Votes inhabit this territory. The Lutheran Finns and Estonians have family names of their native languages. Among them, a new surname was given only to a small number of people who considered their names unpleasant. The Finns chose mostly characteristically Finnish names, in some instances Estonian names and only in one case a German-sounding name. The Ingrians, who had hitherto had Russian family names, got Finnic names: either an Estonian (more frequently) or a Finnish/Ingrian name in 1922 . The new family names represent Estonian, Ingrian or Finnic common nouns, Estonian artificial names, and translations and transformations of former surnames.

The Estonian and Finnish/Ingrian family names are mostly related to nature. The majority of the Estonian-sounding names are connected to designations of plants or their parts: Kask (cf. kask 'birch'), Kuusk ('fir'), Käbi ('cone'), Leht ('leaf'), Lill ('flower'), Sammal ('moss'), Oun ('apple'), and others. Among them, the tree names are the most common. Lillepärg ('garland of flowers'), Roosioks ('rose-spray'), and Õunapuu ('apple-tree') are compounds. Allikas ('fountain'), Järv ('lake'), Kaasik ('birch wood'), Kalju ('rock'), Mägi ('mountain') and others denote natural complexes and natural places. Kivisoo ('stone marsh') and Marjasoo ('berry marsh') are compounds. Kala ('fish'), Kaur ('loon'), Kotkas ('eagle'), Põdra ('elk', gen.), Sääsk ('mosquito') and others are derived from designations of animals. Family names comparable to names of diverse things and materials, like Kangas ('woven material'), Lennuk ('airplane'), Raud ('iron'), and Sirp 'sickle', are not frequent. The names of countries (e.g. Rootsi 'Sweden'), natural phenomena (Tuisk 'snow-storm'), professions (Kalamees 'fisherman') et al. are rare.

Among the Finnish/Ingrian family names, those which denote animals are the most frequent. These include Hauki (cf. Fin., Ing. hauki 'pike'), Joutse (Fin., Ing.joutsen 'swan'), Kajava (Fin. kajava, Ing. kajjava 'gull'), Lohi (Fin., Ing. lohi 'salmon'), Varonen (Fin. varoi 'crow') and others. The family names Koivune (cf. Fin., Ing. koivu 'beach'), Lehtine (Fin., Ing. lehti 'leaf'), Mansik(Fin. mansikka, Ing. mantšikka $\sim$ mantsikka 'strawberry') etc. are comparable to designations 
of plants and their parts. Ahone (cf. Fin. aho 'fallow; treeless plain), Joki (Fin., Ing. 'river'), Tammikko (Fin. 'oak grove') and others denote natural complexes and places. The names of things and materials are reflected by the family names Kauppa (Fin. 'goods, wares'), Padanen (Fin., Ing. pata 'pot'), Silkki (Fin. 'silk') and others. The other name types, like Timmo (a first name), Suomalainen ('Finn') et al., are very rare.

Some new family names resemble former Russian surnames, like Hitro (from Hitrov, cf. Rus. хитрый 'sly'), Pahval (from Bahvalov), and Russian common nouns, e.g. Kalina (cf. калина 'guelder-rose'). The Estonian and Finnish/Ingrian surnames are partly derived also from Russian family names: Kalamees from Kalašnikov, Marjasoo from Morozov. Exceptionally, some last names are borrowed from other languages (German, Latvian, Polish).

Keywords: Estonian Ingria, Finnic languages, onomastics, anthroponyms, family names

\section{Enn Ernits}

Zoomeedikum

Eesti Maaülikool

Kreutzwaldi 62

51014 Tartu

enn.ernits@emu.ee 